\title{
CONGRESO SOBRE URBANISMO MUSULMÁN (TÚNEZ)
}

\author{
Por \\ ABDEL HAKIM EL GAFSI
}

El IV Congreso de Historia y Civilización del Mágreb, organizado por la Asociación Tunecina de Historiadores Universitarios, se celebró en Túnez, en el hotel El Mechtel, del 11 al 13 de abril de 1986, bajo el patronazgo del Comité Culturel National, alrededor del tema "Ciudades $\gamma$ sociedades urbanas en el Mágreb". Investigadores de Francia, Argelia, España, Inglaterra, Estados Unidos, Italia, Turquía y Túnez fueron invitados a participar en los trabajos de ese Congreso.

Al preparar ese Congreso, la Asociación se había propuesto alcanzar dos objetivos principales: confrontar las aportaciones de las disciplinas históricas y arqueológicas, por una parte, y las de geografía, sociología, economía, etnografía, psicología y derecho, por otra; poner en evidencia las relaciones entre ciudad y campo, entre mar y espacio urbano (lugar de habitación, de producción y de intercambio, estructura política, económica, social...). Las comunicaciones han sido reagrupadas en dos comisiones: la de Historia Antigua y Medieval y la de Historia Moderna y Contemporánea. greso.

Vamos a intentar presentar algunas de las principales comunicaciones del Con-

1.-M. H. Cherif, de la Universidad de Túnez, se centró en "El comercio de importación y exportación de Túnez en la primera mitad del XVIII". Insistiendo en lo excepcional de la documentación sobre el tema, puso de manifiesto que el régimen de aduanas hacía una distinción entre musulmanes, cristianos y judíos. También se separaba las mercancías de origen musulmán o no musulmán. A continuación mostró que las mercancías vitales para la economía del país gozaban de ciertos privilegios, como la lana de España, necesaria para la industria de la chechía o "bonetes tunecinos» (sólo pagaba el $9 \%$ de derechos de aduana). También advirtió el carácter temporero del tráfico comercial, según las estaciones del año, y la parte de los países musulmanes en este tráfico. La mejor estación era en verano y otoño y en la época de la Peregrinación a La Meca. En cuanto a las importaciones, los países europeos monopolizaban los 2/3 del tráfico (la lana de España representaba 1/5 de las importaciones).

2.-Ben Achour, investigador del Instituto Nacional de Arqueología y Arte, trató del "Marco urbano, hábitat y estructuras sociales en Túnez en la segunda mitad del 
siglo XIX". El estudio de la Medina y de los dos arrabales de Túnez (Bab Souika y Bab Al Jazira) permite al autor sacar algunas diferencias. La Medina albergaba a las familias de origen antiguo. Entre esas familias se encontraban las de origen español (moriscos), que se habían instalado en Houmet Al-Andalus y Zouqaq Al-Andalus. En cambio los judios se hallaban instalados en la Hara y los cristianos en el barrio franco. Esta diferencia se manifiesta también a nivel de la morfología del tejido urbano y de la organización social. Dos resultados esenciales surgen de este estudio: la separación entre las zonas de hábitat y las de la actividad económica, a nivel de la Medina. y el desarrollo de la ciudad europea con un principio bastante lento de penetración de los europeos en la Medina.

3.- - J. Kefi, arquitecto de la Asociación para la Salvaguarda de la Medina de Túnez, se centró sobre «La sociedad urbana y la organización espacial de la Medina de Túnez». En el contexto de la reforma de la Medina, intentó mostrar el porvenir del espacio histórico, a pesar de la degradación de ese espacio a lo largo del siglo XIX. Ni la creación del Consejo Municipal en 1850, ni la fundación del hospital Sadikí en 1879, pudieron detener la «invasión de los nómadas" y por tanto la ruptura del equilibrio urbano de la ciudad, acentuada por la penetración de los judíos y los cristianos en la Medina comercio de alcohol, desarrollo de la prostitución y de la criminalidad, demolición de parte de las murallas, pérdida de poder de los ulemas y del Cheikh Al-Madina en provecho del poder central y de la policíal.

4. - Sahli Sadok presentó una comunicación sobre "Túnez o el vértigo humano: crecimiento demográfico e implicaciones socio-politicas". Con estadísticas, mostró las características de la explosión demográfica de la capital, con su redistribución espacial y administrativa, y los problemas que engendra (delincuencia, inseguridad, congestión del tráfico,...) Propone soluciones adaptadas a esta nueva situación (creación de empleo, infraestructuras, transporte públicol.

5. - Zannad Traki, «Lo vivido urbano, entre la teoría y la práctica en Túnez». Se trata - según el autor, profesor en la Escuela de Bellas Artes-- de comprender la ciudad de Túnez y particularmente su espacio histórico a partir de un procedimiento nuevo basado sobre lo vivido urbano como fuente indispensable, cualitativa, para enriquecer los trabajos de especialistas en la trama urbana (urbanistas, arquitectos, geógrafos, historiadores, arqueólogos...) Evidentemente, el autor propone, para una mayor eficacia, basar los estudios en encuestas sobre el terreno. A partir de los ukalá (hospederías tradicionales), pudo mostrar claramente las posiblidades de este nuevo enfoque.

6.--Ridha Tlili, "Ciudad y espacio politico. El caso de Túnez". El autor - Director del Centro de Documentción Cultural, del Ministerio de Asuntos Culturales- propone en su estudio un análisis del espacio urbano de Túnez en función del discurso político y sindical. Este razonamiento político y sindical había escogido, antes de la independencia de Túnez, a la Medina o ciudad vieja como campo de acción y de propaganda, pero desde la Independencia la sede del Partido Socialista Desturiano se desplaza a la Rue de Rome, en pleno centro de la ciudad europea. Por otra parte, la Unión de la Industria, el Comercio y la Artesanía deja también la Medina para instalarse en la ciudad europea. La Unión General de Trabajadores Tunecinos, organización obrera, adoptó también la misma táctica trasladándose de la calle Sidi Ali Azzouz a la plaza de Mohamed Ali. A partir de estos ejemplos, el autor analiza las causas y también las consecuencias de esta evolución y sobre todo la ruptura que suponen con la vieja Medina. ¿Se trata de una exigencia ideológica o de la decadencia de la Medina?

7.- Mohamed Jedidi, "La evolución económica y social reciente y la red actual de las ciudades del Sahel tunecino". A partir de la Independencia tunecina de 1956. 
el Sahel conoció una mutación económica y demográfica importante, debida esencialmente a la consolidación de la infraestructura y la transformación de su economia (modernización de la agriculturá, de la ganadería, de la industrialización y del turismo). Esta mutación trajo un desarrollo urbano considerable, a expensas de las superficies consagradas a la agricultura, y una multiplicación del número de municipios en la vida del conjunto del Sahel. El autor de la comunicación se plantea el problema de la eficacia de la multiplicación de los municipios para la vida del conjunto del Sahel.

8. --Bechir Thili, "Grupos de extrema derecha y cuestiones nacionales en Marruecos (1930-1939)». Propone interesarse más por las investigaciones monográficas sobre los grupos nacionalistas franceses, para dejar más en claro las relaciones entre nacionalismo metropolitano y nacionalișmo magrebl, y para comprender también mejor la evolución socio-política de esta región islamo-mediterránea, en su totalidad. Estos grupos de extrema derecha proponen, evidentemente, otro tipo de poder y de sociedad, rechazando al mismo tiempo el comunismo, el sindicalismo y el nacionalismo indígena. Esta ideología, al mismo tiempo colonial y racista, se desarrolla a partir de la prensa de combate y de opinión: "Le Progrés de Fes" y "La Voix Française».

9.--Federico Cresti, "Algunas observaciones e hipótesis sobre la población y la estructura social de Argel durante el periodo turco (XVI-XVIII)". Propone una nueva metodología basada no sólo en la documentación árabe y turca, para evaluar la evolución de la población de Argel, sino también en el análisis del espacio urbano actual (hábitat, densidad,...) para poder completar las informaciones de esos documentos.

10. - Houari Touati, "Nota sobre la organización de las corporaciones de oficios en Argel en los siglos XVII y XVIIIn. Como la mayor parte de las ciudades musulmanas, Argel obedece a una disposición topográfica de los oficios, disposición que respeta al mismo tiempo una ideología (predominancia de la Mezquita Mayor), una ética y una concepción económica particular. Efectivamente, cercanas a la Mezquita se encontraban las corporaciones de oficios no polucionantes, es decir perfumistas, libreros, encuadernadores, etc., mientras que al extremo de la ciudad y lejos de la mezquita se instalaban curtidores, tejedores, etc. La comunicación consagra su última parte al examen de las corporaciones (reclutamiento, promoción, relaciones entre los "maalama", "kalfat» y "sunnaa», división del trabajo, endogamia de clase a partir de algunos ejemplos como el monopolio del trabajo en los baños, en manos de los mzabies).

11. - Lucien Golvin, "Argel en el período otomano", investiga los datos del hábitat tradicional para el estudio de la vida oficial y privada del Jefe del Estado (residencia veraniega del Dey y de sus colaboradores, personajes enriquecidos...) Además, el autor observa que a partir del siglo XIX hay una evolución social, causada por el final del corso, con una decadencia paralela de la ciudad, que se vacía de su población tradicional para llenarse de una población beréber.

12. - André Raymond, "Las características de una ciudad media arabe en el siglo XVIII. El caso de Constantina", analiza, a partir de textos y planos, la evolución urbana de la ciudad, que tuvo una estabilidad política, una prosperidad económica y un desarrollo urbano uniformes. De un análisis minucioso de la trama urbana ledificios religiosos, zocos, hábitat,...) saca dos zonas: una zona central consagrada al comercio y la artesanía, rodeada de otra en la que se desarrolló el hábitat y las "hammas» (barrios). La zona periférica reagrupa un hábitat pobre y una artesanía polucionante. La extensión de la ciudad hacia el norte introduce una cierta dinámica, con la constitución de zocos, instalación de familias judías, etc. Otro aspecto llamó la atención del autor: el antagonismo entre ciudadanos y aldeanos (baldiyya y barraniyya) y los conflictos entre dos familias dominantes, los Abd Al-Mumin y los Fakkun. 
13. - F. Cachi, "Prensa en lengua árabe en Constantina entre 1919 y 1954". A partir de los periódicos "An-Najah», "Ech-Chihab" y "Ech-Chouala" el autor pergeña la vida intelectual de Constantina en esa época, se ocupa de la prensa como medio de acción propagandistica y de reflexión para mantener una cultura árabe-islámica. A partir de esa prensa, el autor intenta reconstruir una imagen de la vida local (vida urbana y rural, conflictos, artesania indigena y competencia colonial, etc.)

14. - Nora Seni, "Ciudad otomana y legislación sobre la presencia en la ciudad de mujeres y minorías étnico-religiosas". A partir de los "firman" y demás edictos, se puede sacar el papel de la mujer y de las minorías religiosas en la sociedad otomana (el caso de Istanbul en particular). La concepción particular de la autoridad política y religiosa frente a la mujer (vestido, prácticas sociales, en las calles y en el espacio urbanol, poder de vigilancia y de castigo concedido a los cadies, imams, muecines, en los barrios, no permite a la mujer tener un papel social pleno (concepto europeo). El autor se interesa después por la vida comunitaria en los barrios o Mehella (separación clara entre comunidades étnicas $y$ religiosas, con signos distintivos $y$ actividades especificas, etc.)

15. - Claude Liauzu, "Orientación y redefinición de las investigaciones francesas sobre las ciudades del mundo árabe». La intensificación de las investigaciones urbanísticas en el mundo musulmán, especialmente en ciudades que fueron áreas culturales y hogar de civilización, impone una reorganización de las investigaciones urbanísticas y una mayor especialización. Los institutos de investigación consagrados a estas preocupaciones se multiplican. Balance y perspectivas de investigaciones en este campo.

16. - F. Georgeon, "Una fuente para la historia humana: la prensa satírica lel caso de /stanbul/)". Después de haber definido el marco político, económico, social, urbano v cronológico (1870-1916) de Istarbul, el autor se ocupa de diferentes problemas evocados por esta prensa (modernización, empuje demográfico, organización municipal, desarrollo del tranvía y creación de un metrol. El autor insiste en el hecho de que el modelo de la ciudad europea aparece mucho en esta prensa, que considera a ese modelo como perfecto e ideal

17. - Taoufik Bachrouch, "El Sahel tunecino: intento de definición de un espacio ciudadano". Región enclavada entre el mar y la estepa, el Sahel tunecino ces una "connurbación»? A partir de esta hipótesis, el autor acomete con mucha argumentación un intento de definición de una ciudad sahelina (degradación de la ciudad antigua y ruptura entre ciudad $y$ contornol. Principio del urbanismo a partir del siglo XI, el Ribat es considerado como el nudo de la urbanización. Es pues un problema de seguridad lo que ha dado el impulso a ese fenómeno urbano. El resultado es que en el siglo XIX el Sahel es una región profundamente urbanizada (zocos, mezquitas, medersas o escuelas, molinos, hammams o baños, hábitat, murallas,...) Además, el estudio de los registros fiscales muestra una población ciudadana (baldivya) junto a una población rural o beduína.

18.--Dominique Chevalier, uLa aportación de Antoine Abdel-Nour al estudio de las ciudades árabes en época otomana. Análisis comparativos y puntualizacionesn. Después de trazar la personalidad de Abdel-Nour, el autor destaca las características esenciales de su obra, centrada en las ciudades de Ash-Sham (región siro-palestina), con un desplazamiento de las ciudades y su población de este a oeste, que ha favorecido a ciudades como Alepo y Damasco. El estudio de estas ciudades permite observar algunas características sociales: parcelación del hábitat, hábitat y reparto confesional, papel de los notables cuyo poder se basa en primer lugar en la posesión de la tierra en este desplazamiento del eje del poblamiento y sobre todo en la introducción del capitalismo financiero, industrial y comercial. 
19. - Rachel Arié, "Una metrópoli hispano-musulmana en a baja Edad Media: Granada nazarí». Una visión histórica, seguida de un análisis de las fuentes árabes y europeas. El estudio de la morfología urbana permite sacar un núcleo central, barrios, cementerios. Prosigue su exposición con el examen de los diferentes oficios, en el centro y en la periferia. Señala más de 40 oficios. Habría tres clases sociales principales: los dignatarios (al-jassa), los juristas alfaquíes (al-ayan) y el pueblo bajo (alamma). La presencia de extranjeros en la ciudad atrae la atención de la investigadora (especialmente de genoveses). El estudio de la población, dadas las diferentes estimaciones, no queda aún suficientemente claro.

20. - C. Sehili, "Las relaciones económicas de Tunicia y Tripolitania con Africa en época hafsí y otomanam. Al principio, el autor se plantea el problema de la política negra de los soberanos hafsíes y otomanos. Evoca a continuación el problema de la documentación, que sigue siendo insuficiente. El despoje de los archivos turcos podrá abrir varios horizontes de investigación, según el autor. El estudio de los itinerarios entre el Norte de Africa y las metrópolis saharianas no permite dibujar cuadros para cuantificar ese comercio. Igualmente no permite dibujar cuadros para cuantificar ese comercio. Igualmente los productos intercambiados por los diferentes centros plantean numerosos problemas.

21. - M. Rammah, "Evolución urbanística de Susa durante los dos primeros siglos de la Hégira”. Este joven investigador del I.N.A.A. ha intentado, en su exposición, seguir no solamente textos árabes de difícil interpretación, sino también trabajos arqueológicos. El estudio de los diferentes monumentos arqueológicos (mezquita mayor, ribat, dar as-sinaa, murallas, alcazaba, trabajos hidráulicos...) ha servido de base para el examen de la vida urbana de Susa en esa época. Finalmente, se puede pensar que la vida urbana conoció cierto estancamiento al principio de finales del siglo II. ${ }^{\circ} \mathrm{H}$.. El autor presenta varias hipótesis sobre el hecho, que exigen evidentemente una reflexión detallada, pero también sondeos arqueológicos en diversos puntos de la ciudad

22. - S. Ferchiou, "Aspectos e hipótesis de trabajo sobre las colonias julias y los pagi de Cártago en el siglo I d. C." El autor propone, junto con las investigaciones realizadas hasta ahora sobre las colonias augustas y su poblamiento, basadas en textos e inscripciones, el estudio de esas colonias en su realidad concreta (excavaciones, recogida de material,...)

23. -A. Ducellier, "Visiones bizantinas sobre el Mágreb en la Edad Media”. Dos aspectos principales han atraído la atención del autor: las fuentes bizantinas posteriores al siglo VI. ${ }^{\circ}$ y los portulanos y guías marítimas. A partir de estas dos fuentes esenciales para el conocimiento del Mágreb, el autor estudia sus posibilidades y sus límites, y saca cierto número de ideas: Bizancio se interesa poco por el Mágreb (territorio de infieles); se conoce bien las costas magrebies por la información de marinos griegos, en vistas a futuras operaciones militares.

Además de estas comunicaciones aquí resumidas, hay que señalar otras de las que no se distribuyó texto o resumen o cuyos autores no participaron directamente al Congreso con su presencia. He aquí la lista de las demás comunicaciones:

24. - M. Fantar, "El urbanismo en la ciudad antigua: Cartago y Kerkouane".

25. - M. Khannoussi, "El poblamiento de la colonia de Simithus (Tunicia)».

26. $-Y$. Thebert, "Permanencia y mutación de los espacios urbanos en las ciudades africanas antiguas».

27. - M. Brett, "La ciudad-estado en la lfriqiya medieval: el caso de Trípolin. 
28. -B. Deumec, "La ciudad y el mar: Túnez en el siglo XV".

29. -A. Filali, "Sobre la conquista árabe-islámica de Constantina".

30. -A. Tlili, "La descripción de las ciudades magrebies en el Kitab Surat al-Ard "Configuración de la Tierra" de lbn Hawqal".

31. $-M$. Terrasse, "A propósito de la casa de recreo en el mundo rural iberomagrebi de la Edad Media. Esbozo de una tipología.

32.-G. Valabrega, "Presencia de los Sarracenos en Varigotti».

33. - I. Fakhar, "Las mutaciones sociales y económicas de las ciudades del Mágreb central (Tahert, Ghardaia y Djerba): estudio comparativon.

34. - A. Badjaja, "De Cirte a Constantina: la permanencia de una ciudad antigua».

35. - Y. Bouaziz, "Tremecén, capital del Mágreb central: sus relaciones culturales con Túnez".

36. -A. Ar-Rayhani, "Las capitales del Mágreb árabe: estudio geográfico y demográficon.

37. - R. Boukraa, «Espacio urbano y violencia: el modelo de la ciudad tradicional y el modelo de la ciudad moderna (Tunicialn. $x \times \geq$.

- 38. -A. Boussefssaf, uLa vida politica en Constantina en la primera mitad del sigio

39. -A. Pozzo, "Constantina en 1944".

40.-A. El Gafsi, "Aspectos de artesanos y oficios andalusies y turcos en diversas regiones tunecinas en el siglo XIX, según los Archivos Nacionales Tunecinosn.

El único español participante, el profesor Míkel de Epalza, no pudo asistir, pero envió su comunicación sobre "Estudios de elementos urbanísticos de Al-Andalus". 